Please refer to the definitive version of this article when citing:

Gössling, S., Cohen, S.A. \& Hares, A. (2016). Inside the black box: EU policy officers' perspectives on transport and climate change mitigation. Journal of Transport Geography, 57, 83-93, DOI: 10.1016/j.jtrangeo.2016.10.002

\title{
Inside the Black Box: \\ EU Policy Officers' Perspectives on Transport and Climate Change Mitigation
}

\begin{abstract}
Transport is a significant and growing contributor to climate change. To stay within 'safe' global warming guardrails requires substantial cuts in greenhouse gas emissions. This represents a global political consensus, but there is evidence that current legislation in the transport sector is not significant enough to achieve medium- and longer-term reduction goals. In focusing on the European Union, this paper investigates the perspectives of twelve policy officers in three Directorates-General (MOVE, CLIMA, ENV) of the European Commission with regard to their understanding of mitigation goals and timelines, responsibilities for policy development and implementation, and perceived efficiencies of these policies to achieve climate objectives in the transport sector. Results indicate diverging and common views on climate policy goals and political responsibilities, as well as barriers to policy-making, including lack of political leadership on climate change mitigation, resistance from member states, the favouring of economic growth over cuts in greenhouse gas emissions, pressure from industry and lobby groups, preferential treatment of aero- and automobility over more sustainable transport modes, policy implementation delays, insufficient forecasting and monitoring tools, and an overreliance on technologies to contribute to emission reductions. In offering a view inside the 'black box' of transport policymaking, the paper reveals fundamental institutional (structural) and individual (agency-based) barriers that will have to be overcome if significant emission cuts in the transport sector are to be achieved.
\end{abstract}

\section{Introduction}

Transport in the European Union (EU28) continues to grow (EC 2015a): in the period 19952013, average annual growth in passenger transport in the EU was 1.0\%, totalling 6,465 billion passenger kilometres $(\mathrm{pkm})$ in 2013 , or $12,700 \mathrm{~km}$ per person. Air and sea transport by EU28 citizens outside the EU are not included in these transport volumes. In the EU, transport accounts for $31.6 \%$ (348.5 Mtoe) of final energy consumption (1,104 Mtoe), out of this $82.8 \%$ is a result of road transport and $13.2 \%$ of intra-EU air transport. Notably, the share of transport emissions increased from $18.8 \%$ in 1990 to $25.3 \%$ in 2012, while the share of emissions from non-transport sectors declined. In the future, continued growth in transport volumes and associated emissions is likely: passenger car numbers, for instance, increased from 163.6 million in 1990 to 248 million in 2013 (EC 2015a). With regard to aviation, Airbus (2015) expects passenger growth in the order of $3.8 \%$ per year in Western Europe, North America and Japan, measured in revenue passenger kilometres (RPK), for the next two decades. Similar expectations have been formulated by Boeing (2015). IATA (2011) projects 16 billion passengers by 2050, compared to 2.8 billion in 2011. Even if growth was lower than these projections by industry, transport's share in EU28 emissions will very likely increase and make it difficult to reconcile growth with climate policy (e.g. Bows and Anderson 2007; Chèze, Chevallier and Gastineau 2013; Kousoulidou and Lonza 2016).

Within the European Union, pledges have been made to reduce emissions of greenhouse gases (GHG) by $20 \%$ by 2020 , and $40 \%$ by 2030 , compared to 1990 . Furthermore, the EU has 
voiced ambitions to implement at least a $27 \%$ share of renewable energy sources in its final energy consumption, and to achieve at least a $27 \%$ improvement in energy efficiency, below a 'business-as-usual' scenario (EC 2015b). The European Environment Agency (EEA 2015a) is tracking these targets and concludes that GHG emissions have already declined by $19.8 \%$ below 1990 levels, i.e. they are in line to achieve a $24 \%$ reduction by 2020, more than necessary to meet mitigation commitments ( $20 \%$ by 2020$)$. A critical assessment of the EEA report reveals, however, that the influence of economic growth as a driver of emission growth has been negative or neutral in most years of the assessed period (2005-2013), while there are also economies that have experienced reversing emission trends. Germany, for instance, with a self-declared goal of a $40 \%$ emission cut by 2020 in comparison to 1990, has recorded growing annual GHG emissions in the years 2012 and 2013 compared to 2011 (Umweltbundesamt 2015). Compounding this, measures in the EU to reduce emissions are likely to have had a comparably low or even negative cost in the last decade, and these costs are going to increase significantly over time (IPCC 2014). Consequently, there is evidence that a continuation of decarbonisation pathways may be complicated by various factors.

Even though these issues are not acknowledged by the EEA (2015a: 10), the organization does emphasize that "member states... will have to increase considerably their efforts to meet longer-term energy and decarbonisation objectives for 2050", noting that reductions between 2030 and 2050 will have to be three times steeper than reductions between current and 2030 levels (Figure 1), in a situation where mitigation becomes increasingly expensive. As outlined by the EEA, a major obstacle to achieving longer-term overall mitigation objectives will be transport, as emissions from this sector have increased - not declined - by $19.4 \%$ between 1990 and 2013. Compounding this, the EEA outlines that GHG emissions covered by the EU Emissions Trading Scheme (ETS) are essentially from industrial installations, i.e. largely irrelevant for the transport sector. The EEA emphasizes, however, that the EU ETS has covered emissions from intra-EU aviation since 2012, and concludes that further reducing emissions from transport will require mitigation actions at the national level, driven by a mix of EU policies.

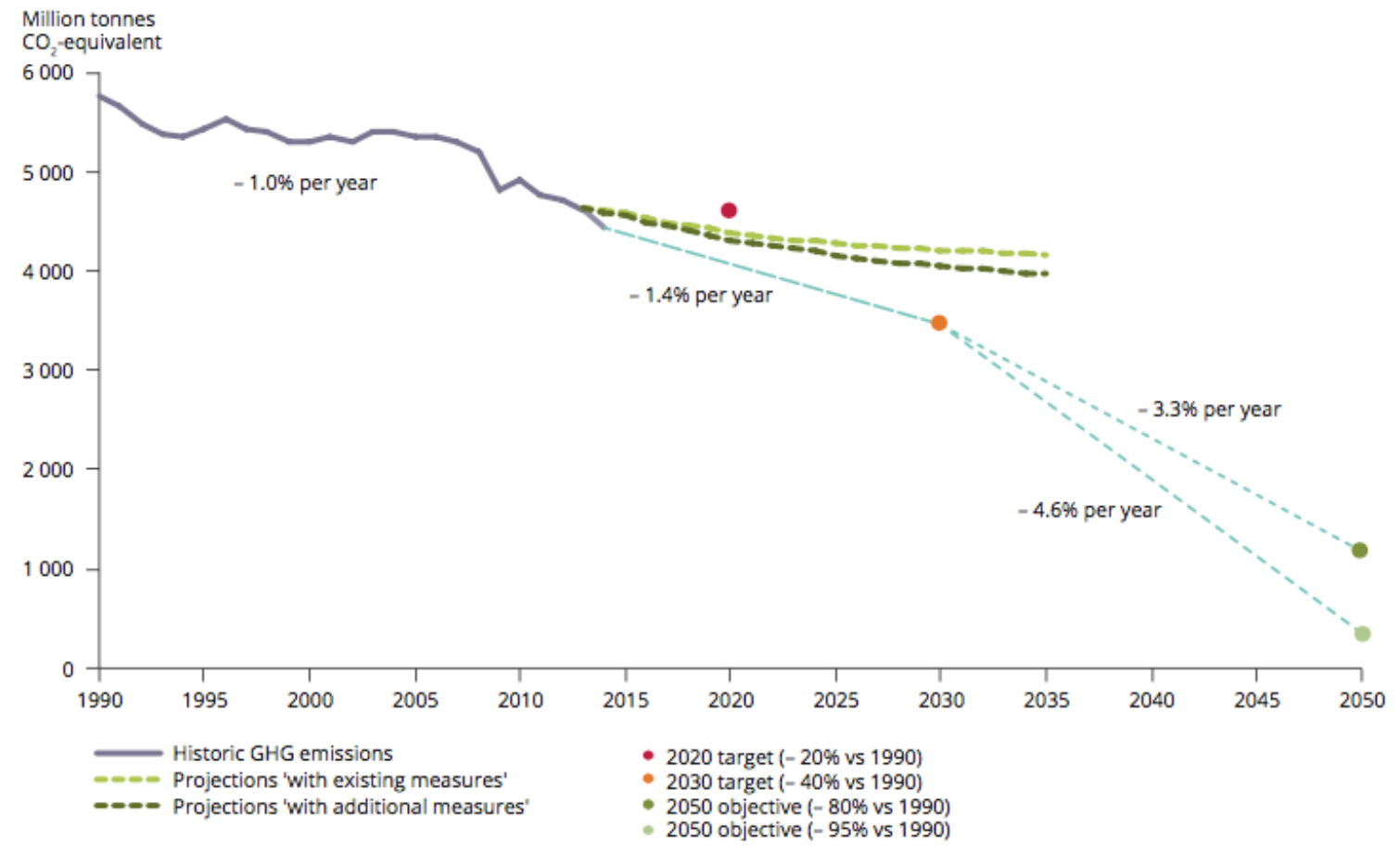

Figure 1: Emission reductions pathway, EU28

Source: EEA 2015 
Official pledges of emission reductions by the European Commission (EC 2015a) for the European Union can thus be compared with mitigation pathways outlined by the EEA (2015a), and goals specified in the 2011 Transport White Paper (EC 2011). While the EEA seems to expect the EU ETS to achieve the greatest share of overall emission reductions in the short-term future (63\% of needed cuts in the period 2013 and 2020), the European Commission (EC 2015a) highlights that transport emissions would have to fall by $67 \%$ by 2050 compared to 2012 in order to meet the Transport White Paper (EC 2011) transport emission reduction objectives for 2050, defined as a $60 \%$ decline in GHG emissions compared to 1990 (see also EEA 2015b). Given EU28 ambitions to reduce overall emissions by $80 \%$ by 2050 , this implies that the transport sector will make a smaller contribution to decarbonisation than other sectors. Yet, the current view by EEA (2015a) is that transport emissions will decline by only $0.7 \%$ per year between 2013 and 2020, as a result of 'key EU policies' including biofuels, infrastructure charging for heavy goods, mobile air conditioning, $\mathrm{CO}_{2}$ from cars, clean and energy-efficient road transport, and $\mathrm{CO}_{2}$ from vans.

In comparison, the EC (2015a) in summary has implemented transport policies as follows:

- Aviation has been included in the EU Emissions Trading System (ETS);

- A strategy is in place to reduce emissions from cars and vans, including emissions targets for new vehicles;

- A strategy for reducing heavy duty vehicle fuel consumption and $\mathrm{CO}_{2}$ emissions;

- A target is in place to reduce the greenhouse gas intensity of fuels;

- Rolling resistance limits and tyre labelling requirements have been introduced and tyre pressure monitors made mandatory on new vehicles;

- Legislation encouraging national authorities to deploy gas and electricity infrastructure; and,

- Public authorities are required to take account of lifetime energy use and $\mathrm{CO}_{2}$ emissions when procuring vehicles.

In summary, the EU currently relies on two major legislative instruments to reduce emissions, i.e. the EU ETS, imposing caps on $\mathrm{CO}_{2}$ emissions of large emitters (Directive 2009/29/EC), as well as legislation for sectors not covered by the EU ETS on a national level, covering transport (Decision 406/2009/EC). While inclusion of aviation in the EU ETS limits the impact of additional growth in this sector by forcing other sectors to reduce disproportionally greater emission volumes, the system only covers intra-EU air travel. With regard to other legislation, measures as currently implemented or planned for the period 2013-2020 appear to be solely focused on technological innovation, with no specific consideration of either market-based initiatives including taxes and duties (carbon pricing) to initiate changes in transport use, or stripping away fossil-fuel subsidies. Yet, both of these have been singled out as key issues that would have to be addressed in order to significantly reduce fossil-fuel dependencies and emissions of GHG (IEA 2015; IMF 2015; OECD 1999, 2008, 2015). Concerns that current policy measures are not far-reaching enough have been voiced frequently, and it has been noted that fundamental barriers to achieving longer-term climate mitigation objectives in the transport sector still remain (e.g. Anable et al. 2012; Banister 2008, 2011; Chapman 2007; Marsden and Rye 2010).

Analyses of this impasse have had a starting point in the observation of an 'implementation gap' (Banister and Hickman 2013), defined as an insufficient transfer of scientific knowledge into policy-making and implementation. The implementation gap also inspires this paper, which seeks to better understand reasons for the absence of credible decarbonisation policies in the EU transport sector. So far, obstacles have been identified in the societal and political 
focus on ecological modernization and neoliberal governance, i.e. belief systems comprising elements of future technological breakthroughs and significant voluntary behavioural change, which are approaches that have been questioned in terms of their relevance in contributing to significant emission reductions (Barr et al. 2010; Chapman 2007; McKercher et al. 2010; Higham et al. 2014). Forms of neoliberal governance have also been linked to 'transport taboos' (Gössling and Cohen 2014), defined as decisions that constitute a risk to political decision makers because they would initiate fundamental change and thus upset 'order', i.e. existing power structures. Taboos have been discussed as cognitive and affective barriers to the decarbonisation of transport systems, including in particular the industry-led discourse that decarbonisation is in progress on the basis of technological innovation. Yet, if taboos cannot be overcome, this will confirm 'path dependency' and social lock-in in the transport sector, i.e. a situation where actions of the past condition future outcomes, and where alternative futures become impossible (Hall 2013; Imran and Pearce 2015; Schwanen et al. 2011).

These apparent contradictions in transport policy demand a better understanding of transport governance structures, that is, the "regimes of laws, rules, judicial decisions and administrative practices that constrain, prescribe, and enable the provision of publicly supported goods and services" (Lynn et al. 2001: 7). The transport system in the EU is shaped at various levels, including local and regional administrations, national governments, and the European Commission's Directorates-General (DGs). At this highest supranational level, EUwide climate policy strategies are developed, and recommended to member states. Climate policies of the EU are documented in the 2030 Climate and Energy Framework agreed by the European Council (EC 2015b). This Framework does not include transport-specific targets, which are instead set out in the European Commission's Transport White Paper (EC 2011). Transport is a sector relevant to the work of different DGs, and transport governance in the EU consequently involves multiple actors in an institutional network of organizations comprising governmental and non-governmental entities with potentially contradictory goals.

As Marsden and Rye (2010) emphasize, given observed growth trends in transport, this is a sector in which cutting absolute emissions is fundamentally more difficult than most other sectors, requiring action at all levels of government. Although the supranational governance levels of the EU has the potential to critically influence governance at all levels, there is a notable gap in research discussing the internal workings of transport policy-making in the European Commission. This is despite considerable literature exploring the European Commission's internal operations and the dynamics of EU policy processes more generally, including decarbonization in other sectors (e.g. Dupont and Oberthür 2015; Hartlapp, Metz and Rauh 2014; Kassim et al. 2013). This research consequently addresses the perspectives of policy officers across three DGs of relevance to the transport sector, with a specific focus on climate policy. Within the policy cycle, it primarily seeks to understand how policies are developed, but also considers their implementation and evaluation (Howlett, Ramesh and Perl 2009), and whether within these components there are barriers to effective transport policy. Findings are discussed against the background of observed 'implementation gaps' and 'path dependency', with the overall goal to discuss whether there may be further obstacles, whether those be institutional (structural) and/or individual (agency-based), than the affective and cognitive barriers identified in earlier research.

\section{Method}

In order to gain insights into the internal workings of transport policy-making processes in the European Union, twelve semi-structured interviews were carried out with policy officers in three DGs: CLIMA, MOVE and ENV. DG CLIMA is responsible for the formulation and 
implementation of climate policies and strategies, including the EU ETS, and the monitoring of national emissions by EU member states (EC 2015c). DG MOVE defines its objectives as to promote mobility that is "efficient, safe, secure and environmentally friendly and to create the conditions for a competitive industry generating growth and jobs" (EC 2015c, no page). DG ENV sees itself as responsible for EU policies on the environment, also controlling that member states apply EU environmental law correctly (EC 2015d). A limitation of the research design is that the analysis relies on the perspectives of DG policy officers, excluding potential interviewees from other institutional backgrounds who are involved in the EU governance network (e.g. Members of European Parliament, industry stakeholders).

An initial contact in one of the three DGs was the starting point for a snowball sampling approach, in which each respondent was asked to provide new potential contacts for interviewees from within the European Commission who would have a relevant point of view on climate change policy and transport. These were contacted on a rolling basis, and a date/time for a telephone interview was agreed upon with those willing to be interviewed. The sample is therefore not representative of the three DGs, as interviewees were selected based on the recommendations of other interviewees, with the exception of the initial contact. While other DGs, such as DG GROW are relevant to climate policy for transport, the snowballing technique did not lead to interviews beyond DGs MOVE, CLIMA and ENV. The distribution of interviewees between the three DGs is furthermore uneven, and their roles within the DGs vary, but all are relevant to the design and implementation of transport and climate policy within their respective DG, as opposed to contributing to policy coordination between DGs. Further detail of their specific distribution and role is withheld for purposes of anonymity, as discussed below.

Interviews were carried out in the period November 2014 - August 2015, and lasted between 20 and 40 minutes. All interviews followed the same interview programme. After an introduction of the researchers and their respective universities, the topic of the research was introduced in a general way ("EU climate policy with regard to transportation"). Respondents were assured anonymity, including assurance that any quotes would be anonymous, and job roles would be omitted. Interview questions covered employment length in the respective DGs, educational backgrounds and current responsibilities, before focusing on more general aspects of EU transport policies. Questions included the main tasks of the respective DGs with regard to climate change mitigation in the transport sector, as seen from the viewpoint of the respondents; their view on mitigation goals within the DGs; whether the EU is on track to reduce emissions; responsibilities to implement EU climate policy; obstacles to achieving EU policy objectives, and suggestions as to how such obstacles may be overcome. A last question encouraged respondents to take up any issue that may have remained unaddressed.

All interviews were digitally recorded and a blinded thematic analysis approach in manually interpreting the empirical material was used (Patton, 2002), which involved reducing the empirical material into categories guided by the participants' narratives and the identification of emergent themes (Miles and Huberman, 1994; O'Reilly 2005). 'Analyst triangulation' (Patton, 2002) was applied to ensure trustworthiness by checking for congruity of interpretations, blind spots and multiple ways of interpreting the empirical material (Lincoln and Guba 1985). This process involved an analysis of the material on an individual basis, with subsequent comparison and exchange of interpretations by the research team members. Through this process congruent interpretations were agreed upon and contrasting interpretations identified to enrich the analyses. Verbatim quotations from participant interviews were used in thematic interpretations in order to present the data extensively (Decrop, 2004). Included quotes were sent to the respective respondents to make sure they 
considered themselves unidentifiable. This led to the further anonymization of the respondents' respective DG, wherein respondents were pseudonymed as R1-R12. Respondents were finally sent a full first draft of the paper to comment on prior to submission, so as to further ensure the quality of the analysis and interpretation. Extensive sections of interviews have been included in the analysis to show variation and consensus in opinion, as well as complexities in the views expressed. The presentation of the empirical material is followed by a separate discussion section because it allows the reader to first consider the implications of a range of statements by the respondents, before their significance is discussed in further depth.

Findings are presented within the conceptual framework of a 'black box', with the objective to generate new insights in transport policy-making processes within the European Union and to identify institutional (structural) and individual (agency-based) barriers to significant decarbonisation policies. The concept of a 'black box' is derived from system theory and modelling (e.g. Suykens and Vandewalle 1998), and resembles a system viewed in terms of inputs causally related to outputs, without knowledge of the system's internal workings. Even though EU policy making has been investigated from a wide range of perspectives and disciplinary angles (e.g. Banister et al. 2000; Bart 2010; Michaelowa 1998; Kohler-Koch and Eising 1999; Richardson and Mazey 2015), this paper takes a different approach in that it investigates policy officers' own viewpoints on the workings of EU policy making, thus providing a perspective from inside the European Union.

\section{Findings}

The findings indicate that all respondents had worked at least six months and up to 20 years in the respective DGs, and in most cases for several years. Even though the number of interviews conducted does not permit a comprehensive understanding of views and perspectives inside DGs, interview analysis suggests that there is considerable disagreement within the DGs as to: 1) how climate mitigation goals are defined; 2) whose political responsibility the development and implementation of mitigation policies is; 3) whether current and planned policies will be sufficient to achieve short- and longer-term climate change policy objectives; and 4) whether leadership on mitigation goals is sufficient. These four themes may be considered 'internal' policy issues, as they suggest that there is a degree of confusion between and within DGs regarding transport policy mitigation objectives, responsibilities, and strategies. With regard to what may be considered 'external' issues, there are common as well as differing perspectives between and within DGs regarding barriers to policy development and implementation. These include: 5) opposition from member states; 6) competing growth objectives; 7) pressure from industry and lobby groups; 8) preferential treatment of specific transport modes; 9) policy implementation delays; 10) lack of policy target monitoring; and 11) overreliance on (future) technology to solve the problem.

\section{No coherent understanding of mitigation goals and timelines}

Analysis reveals at least three different perspectives on mitigation goals exist, i.e. that there is no mitigation goal for transportation; that transport mitigation goals correspond to EU climate policy goals more generally; and that mitigation goals for transport are outlined in the 2011 EU Transport White Paper (EC 2011). There are also different perspectives regarding timelines, that is, as to which mitigation goals need to be achieved over short (2020), medium (2030) and longer-term (2050) time horizons.

R8 starkly reflected a perspective that no mitigation exist for transportation: 
...your basic question was whether there was a specific transport related reduction objective and there is none - at least no legally or politically binding one as adopted by the Council or EU Member States.

Sharing this view was R3, but with the caveat that this is not unique to the transport sector, as no sector has its own specific climate policies within the European Commission:

I don't think there is a particularly coherent EU transport and climate policy...we don't have sector specific climate policies in my view in any sector as EU climate policy does not tend to have a sectoral focus.

Diverging from this perspective, one respondent suggested that transport mitigation goals correspond to EU climate policy goals more generally, but was not able to specify what mitigation goals should be achieved beyond a short-term (2020) horizon. Further ambiguity derived from whether direction on decarbonization for the transport sector was to be taken from the Commission's broader Low Carbon Economy Road Map (long-term), recent internal goals for 2030 (medium-term), or the short-term target:

I think you could say that the long-term aspiration is set out in the Low Carbon Economy Road Map. And then of course we have recently adopted communications looking at 2030 and overall goals. And of course for 2020 there was the $20 \%$ reduction target that was adopted back in 2008. So you have sort of various goals over the short to long-term future. (R11)

Both the perspectives that there is no mitigation goal for transportation and that transport mitigation goals correspond to EU climate policy goals more generally, overlook the mitigation goals that were set for the transport sector in the 2011 EU Transport White Paper, which was clearly articulated by R7: 'The target we have fixed in the white paper is 60\% reduction of $\mathrm{CO}_{2}$ by 2050.' But another responded who remembered the goal differently suggested the same timeline sought a much higher percentage reduction:

...our main targets are set out in the transport white paper... as a long-term target as the decarbonisation for 2050, just off the top of my head $85 \%$ and there are some more indicative targets for 2030 set for the different modes.

While the causes for disagreement are not apparent from the interview material, to an extent variation may be due to interviewees differing in whether they point to indicative, aspirational or legally binding targets. Nonetheless, the findings suggest that across the DGs there is a lack of agreement as to what mitigation goals should be achieved by the transport sector, where the mandate to mitigate comes from, if existing at all, and over what timelines changes must happen. This is set within a context of split views over which DGs are responsible for policy development.

\section{Diverging views on responsibilities for policy development}

Interviews reveal widely divergent perspectives on responsibilities for developing climate policies for the transport sector, spanning agenda-setting, policy formulation and decisionmaking (Howlett et al. 2009), which are either rejected or assumed by individual policy officers in the three DGs, though perspectives of shared responsibilities do also exist. Perspectives are not necessarily contradictory, however, as individual officers may refer to specific aspects of legislation. 
Viewing policy responsibility for the natural environment as separate from that of climate change, R1 distanced DG ENV from responsibility for transport emissions: 'DG ENV has no competence in the theatre of greenhouse gases, this is the field of DG CLIMA.' This seemed to be a shared understanding by some: '...our [DG CLIMA's] main task is of course development and implementation of the climate policy (R10). Yet as R9 voiced, 'I think we as DG MOVE are the prime responsible of setting the overall [transport] policy.' In contrast to DG MOVE taking responsibility for climate policy for transport, another respondent contradicted this view:

I was happy that we had a clear and specific target finally for transport in the 2011 White Paper, and when I saw that nothing was happening on our delivery to focus on achieving anything in that area, I did ask a number of people inside the DG [MOVE] and some of the people who were closest said it's the responsibility of DG CLIMA, which is an unbelievable answer. (R12)

These perspectives suggest that there is a considerable lack of clarity between policymakers within DGs CLIMA and MOVE as to who is responsible for the development of climate policy for the transport sector. This may be because DG MOVE, despite seeing itself as setting the overall transport policy, feels partially absolved from addressing climate policy due to the explicit focus on climate change in CLIMA. This is also evidenced by the respondent from DG ENV who viewed greenhouse gases as the domain of CLIMA, thereby artificially divorcing climate change from the wider domain of environmental issues.

R11 and R2 offered differing, more complex views, explaining how the responsibility is shared among multiple DGs, but mainly CLIMA and MOVE, while referring to specific aspects of legislation:

DG Climate Action [CLIMA] of course is responsible for various pieces of legislation, like aviation within the ETS and the road vehicle $\mathrm{CO}_{2}$ regulations, and fuel regulations. But then DG MOVE has a certain responsibility in terms of other transport policies at EU level. ... So I think you could say shared between the Commission and the member states, but actually within the Commission it's largely DG MOVE and DG Climate Action that share that responsibility... (R11)

...for transport it's shared between DG MOVE to some extent the former DG ENTERPRISE - now DG Grow - and DG CLIMA...but at least three are mainly in the driving seat for implementation of climate policy... (R2)

Given the complexity of a policy field in which there are various sub-sectors, and policy mechanisms ranging from command-and-control to market-based and voluntary measures, it is evident that, overall, policy officers lack a clear understanding of the distribution of responsibilities for developing climate policy for the transport sector. In addition to disagreement over who is responsible, for how much, and by when, policy makers furthermore varied widely in their opinions as to whether existing policies would be effective.

\section{Effectiveness of policies to achieve emission reduction goals}

A key question is whether EU policies will be effective in achieving emission reductions in line with decarbonization goals. Widely varying perspectives exist in this regard, which is notable because it shows a lack of internal consensus over whether policy progress on transport climate goals has or will be sufficient. A limitation here is that policy efficacy in 
terms of variation by DG cannot be compared, by highlighting which interviewees are speaking on behalf of which DGs, as doing so could jeopardize anonymity.

Policy officers stated that they are unable to judge mitigation policy efficiencies (e.g. 'To be honest I don't know' (R3); that policies are uncertain; unambitious; or the opposite, certain to be successful. Several policy makers expressed uncertainty and skepticism with regards to meeting deadlines, the suitability of objectives, and whether policies would be implemented by member states:

I think we are not on track when it comes to the deadlines, maybe because of the economic crisis, or we may have to revise some of the objectives in the light of concrete progress made so far. (R4)

...we will need to see how those [policy initiatives] will be received by member states and how they will be implemented by the member states. But if you actually do ask for my assessment as we speak I would be relatively skeptical. (R8)

This uncertainty was accompanied by a feeling that existing policies lack sufficient ambition, and are not aggressive enough:

For the long-term targets I think it's very hard to say, my personal honest opinion is that I still have a bit of an issue that the policies are still, let's say, aimed at low hanging fruits. (R9)

R12 was also doubtful that policies would be sufficient to meet the Transport White Paper's (2011) goal of delivering a 60\% reduction, questioning DG MOVE's level of commitment to do so:

I think we haven't really got a proper understanding or strategy for the transport part. ...60\% greenhouse gas reduction target is the headline target in the White Paper, if you look into the reality of the work that DG MOVE has done since 2011 or the internal work to support the White Paper, I don't think you'll find any convincing strategy or commitment to delivering on the $60 \%$.

This questioning of the viability and effectiveness of the decarbonization strategy for the transport sector was not shared by all the policy officers. Others felt quite the opposite, although still set within the context of some uncertainty, such as R6: '...it's difficult for me to judge the greater context as to how the overall targets are being achieved there but, but yes I would say yes...' Others displayed far less doubt:

Well the 2020 one is almost achieved...For 2030 we don't really have the legislation in place yet, that's something still under discussion or even to be proposed, but in principle I think it's perfectly achievable, yes. (R11)

Given diverging perspectives on mitigation objectives, this range of opinions may have been expected. It emerged that these varying opinions to some degree are linked to perspectives that the European Commission lacks sufficient leadership on transport emissions reduction.

\section{Insufficient leadership on delivery of emission reductions}

The final 'internal' issue that emerged, as outlined by various policy officers, is that problems persist with regard to leadership on multiple levels, i.e. both within DGs, between DGs, and 
within the European Commission. R12 provided a detailed account of this perceived problem, both within her/his own DG, and at the broader level of the Commission:

I've tried to ask that question [regarding leadership on emission reductions] inside the $D G$ and it's a completely unclear answer. ...We also have a new Director General here as well since the spring... and also I still have not yet seen anything from him indicating any personal commitment or drive to deliver on the White Paper target.

A lack of sufficient leadership was viewed as a significant obstacle for taking climate change policies forward: '...the EU has set itself many goals, many targets and the multitude of various policy objectives but to some extent there is insufficient coordination' (R8). It was suggested that competing interests among ministers can slow progress and that a strong leader that can bring individual agendas in line with climate mitigation objectives was needed:

...personalities take over and individual ministers like to think that their portfolio is more important than their rivals there so ultimately you need a strong person with oversight that can knock their heads together and make them listen... (R6)

...if there was a style of leadership either from the Commission or the Director General that was really to give a strong kind of active policy direction that could change things around. If it was really made clear that this had to be done. (R12)

However, it appears that the leadership needed to bring conflicting interests on transport decarbonisation, into harmony, at both intra- and inter-DG level, is presently lacking. The absence of leadership, however, is only part of the explanation for a lack of coordination and coherence in the approach to transport climate policy being taken by the DGs, as demonstrated by the other internal points of disagreement discussed above. Nonetheless, effective leadership remains a significant barrier to the co-ordinated development of a policy agenda for transport emissions reduction. But even if this were to be achieved, 'external' issues that affect both the development and implementation of policies remain.

\section{Opposition from member states}

Findings suggest that there is a challenge to gain buy-in from the individual member states, connected to a feeling that within the EU, member states show resistance to engage with emission reduction targets, partially as a result of a lack of an understanding of the seriousness of climate change, but partially also because economic growth is considered more important.

R4 clarified how it is up to the European Commission to develop climate policy, but the implementation is up to the member states 'playing ball':

...it's the member state that need to achieve the goals, you can set a wonderful strategy but if the member states don't play ball you will not achieve it. (R4)

Explanations given for why member states may be reluctant to implement policies included both a lack of appreciation of the seriousness of climate change, and a desire to delay or disrupt targets because of competing objectives: 
I think that at the moment there is really a lack of understanding of the problem and although everyone speaks in general of climate change issues around the world, it still seems that in many countries the understanding is really limited. (R10)

[There is] Interference from the member states. ...in postponing and exerting political pressure to postpone targets. That there should be no targets at all. (R5)

Interference from the member states on targets was perceived as largely stemming from a prioritizing of economic growth over mitigation goals. While it is likely that member states may also not implement transport climate policies for reasons such as resisting a feeling of being 'dictated to' by the EU, or because they believe that policy design and implementation will be more appropriate at more local or 'lower' levels, these explanations unsurprisingly did not emerge from perspectives internal to the DGs. However, the perspective that economic growth and mitigation goals are competing objectives was not exclusively associated with the member states, but was also evident within the DGs themselves.

\section{Competing growth objectives}

Interviews reveal considerable consensus that climate change mitigation goals compete with objectives of transport growth, which is viewed as closely linked to economic growth. Questioning of the assumption that transport growth and economic growth are closely correlated, or recognition that climate policy can drive innovation and positive economic impacts, were notably absent from the interview material. The primacy of economic goals versus mitigation ones was linked to the objectives of the particular DGs:

Internally...you'll always get these diverse views of the importance of environmental actions...DG CLIMA, their number one goal is to have the minimal motor emissions, $D G$ Enterprise their number one goal is to maximize industry. So you're always going to have these contradictory forces pulling in different directions there. (R6)

It was suggested that policy officers focusing on transport policy gave too much primacy to economic objectives, at the expense of environmental and social concerns. This was considered a major obstacle to achieving climate objectives:

...I think people that work in transport policy often see their job as facilitating transport, they don't see it as managing transport within a wider set of social and environmental objectives. And I think that's a big part of the problem in fact. (R11)

Policy officers who took the view that emissions reduction should not come at the expense of economic growth offered justifications largely centred on the importance of industry in Europe remaining competitive. This varied across scale and transport mode. For instance, R4 pointed to the importance of staying competitive with the Gulf airlines, who enjoy extremely low fuel prices, but also to the role of cars in society, in relation to public transport, which has implications for Europe's car manufacturers:

...there are problems of for example, the competitiveness of the industry like for example the aviation industry, aviation is under great pressure from other airlines, for example the Gulf airlines they pay next to nothing for their fuel and so there is a certain pressure to keep fuel prices low which is of course not in line with a necessity to give the right price signals to reduce consumption of fuel. 
Then there's issues related to how public transport is organized and the public car in particular, so you'd need policies to reduce the use of the public car, this is also a contradiction of tension with the objectives to stimulate and support the car industry. ... if you reduce transport the economy doesn't grow.

These concerns were encapsulated, particularly for DG Move, by R8, who summarized that the DG is concerned about mitigating emissions, but not at the expense infrastructure development, which was linked to Europe's overall economic development:

One of the main tasks of DG Move is to contribute to mitigation of greenhouse gas emissions and to devise transport policies such that this objective is achieved without hampering mobility and without hampering the further development of transport infrastructure which is important for the whole economic development of the union and its member states.

It emerged, however, that the importance given to supporting industry, and hence economic objectives, over environmental ones, is to some extent driven by industry interest groups.

\section{Industry and lobby group influence}

Policy officers also expressed views that emission reduction policies are strongly opposed by industry and lobby groups, and consequently difficult to implement. R11 emphasized that '[T]here are very powerful industries. That's one clear obstacle.' Decarbonization was viewed as a threat to some major players in the transport industry, such as the car industry, and is consequently resisted:

...obviously there is simply an obstacle to overcome resistance from those who will... see themselves as losers of such climate change policies. I mean it might be another discussion whether this is right or wrong but obviously industry, car industry etc. come to mind. (R8)

The DGs were criticized for being too susceptible to industry interests in the policy process, even in the absence of sound evidence:

I think a big part of the problem is that politicians are too willing to listen to industry even if industry doesn't come with good evidence, if they just come and complain that something is going to destroy their industry one way or another, politicians are too willing to listen to it. (R11)

This is further complicated by the fact that DGs have to consider industry views from the outset, with a share of policy officers having been recruited from industry, although recognizing that policy officers coming into DGs CLIMA and ENV will often be from professional backgrounds likely to make them more sympathetic to environmental agendas. This may imply that industry perspectives already exist or even dominate views in DGs, especially DG MOVE, and provides further evidence that climate change is considered secondary to economic growth.

DG MOVE is rather captured by industry interests. So it's more following the transport industry's line rather than being an impassionate regulator. I think DG MOVE is a bit scared of negative reactions from industry. ...I used to think it was because you used to have a lot of senior people that were from the industry themselves, so of course if you are recruiting senior people from industry themselves 
they come with a certain industry view... Really DG MOVE seems like a transport industry supporter...rather than being someone who should ensure the transport industry delivers on the needs of citizens or business or broader society or EU policy goals. (R12)

This reflection on the internal composition of the DGs, particularly DG MOVE's sympathy towards industry interests, is further complicated by the suggestion that the individual attitudes and behavior of policy officers themselves presents an additional barrier to the development of transport policies that may reduce emissions, but also threaten lifestyles that depend on cheap access to flying:

....and of course many of us excessively travel a lot, many of us travel by plane excessively, so maybe that's maybe one reason for the bias [of not focusing on policies for aviation]. There's a huge focus on aviation here and that's why I think it's one of the most glaring examples of how you know we have a headline target for a $60 \%$ greenhouse gas reduction but on the other hand we're overseeing a massive expansion and liberalisation of airports and aviation. (R12)

The singling out of aviation as a 'glaring example' extended to a wider perception that aviation, for instance, enjoys unfair protection against mitigation policies compared to other transport modes.

\section{Preferential treatment of specific transport modes and the transport sector}

Policy officers express concerns with regard to issues around taxation of fuel and the perceived economic importance of certain transport modes resulting in an uneven playing field, with some transport modes viewed to be given special protection from emission reduction policies. There is a perceived lack of discussion of these issues within DGs:

I see as an issue is always related to the pricing and there are certain things that are exempt for taxation the fuels in aviation, of maritime which make it just very hard to get a level playing field there between the modes in terms of cost of fuel. (R9)

...no one is really challenging the thinking, so the fact that we have this taxation of fuels for road and rail but we don't have taxation at all for aviation creating another huge imbalance, none of these interesting and big topics are really discussed internally. (R12)

However, this is not viewed as exclusive to aviation or maritime transport, but as pertaining to more carbon intensive modes of transport more generally, including also road transport. Thus a contrasting view emerged that the road transport sector is too protected as well:

...the road transport sector the infrastructures are undercharged perhaps more than other modes of transport and so you don't create a level playing field between modes and it becomes very difficult to favor modes that are less carbon intensive. (R4)

On a broader level, there is also an understanding that the transport sector should contribute less to emission reduction goals than other economic sectors.

I'm also kind of amazed that the other industry sectors that are reducing emissions aren't doing a more active campaign to say we don't mind making our contributions but transport is getting an easy ride. If I was the electricity sector or I was the housing 
sector, who are making significant investments and are on track to deliver their reductions, you know why don't they say well you're over-pressing us because transport is not contributing. (R12)

Yet no explanation is offered as to why the transport sector should be allowed to lag behind other sectors in emissions reduction. Policy officers do, however, provide a number of reasons for why policy implementation is delayed.

\section{Policy implementation delays}

The analysis uncovers perceptions that bureaucratic processes within the EU and negotiations with external stakeholders, including member states, delay policy development and implementation. While this is likely not a barrier that is unique to the transport sector, it nonetheless emerged as a significant factor slowing progress. R10 provided insight into a roadblock hindering the development of a global market-based measure for aviation emissions:

So next year...ICAO [International Civil Aviation Organization] is supposed to have a proposal for a global market-based measure which would address all international aviation emissions. ... But I have to be very honest, the ICAO process is really slow and still at the moment there are quite different views of different states how to deal with that issue ...the problems that we see and we face at the international level, the interests of different states and the different status of the aviation sectors, these are the main obstacles that are preventing us to develop very robust measures at ICAO that will be acceptable to all.

This quote illustrates how the differing views of member states, industry interests, and extraEU stakeholders compound to delay policy implementation. But the delays are not just external, as internal negotiations and preparations are also viewed as a barrier slowing policy progress:

...these are high level targets that we are mostly aiming at and of course, that requires rebalancing individual policies some of which are being implemented very effectively, some of which are getting stuck either in negotiations or in preparation. (R9)

This policy officer further elaborated that the taxation of fuels is basically set at the level of member states and that consequently '...the EU just has very limited power...and it goes rather slowly or it's blocked completely', thereby preventing the pricing of fuels at 'real costs'. The implications of this relate to the finding above on opposition from member states, illustrating how member states may not just have more appropriate 'local' policy solutions, but even access to tax and spending legislation levers that the EU does not. Policy proposals based on carbon pricing, which would be a key strategy in achieving reductions, thus cannot be advanced at the supranational level at all.

While bureaucratic processes and external stakeholders were identified as a key dimension delaying policy implementation, the lack of ability to monitor targets and forecast emissions emerged as a further crucial issue.

\section{Lack of policy target monitoring}

Various policy officers outlined that there is a scarcity of data, and that it is difficult to know whether the EU is on track to meet targets. While this was invoked by interviewees as one barrier to effective climate policy for transport, overcoming this barrier through effective 
monitoring does not suggest that the fundamental policy development and implementation barriers identified in other sections of this paper would be significantly easier to overcome. Indeed, pointing to a lack of effective target monitoring can be viewed as a way to escape responsibility for managing progress towards a target, i.e. shifting blame to a lack of measurement. This includes data that would might be generated internally, or by external sources, evaluating the effects of specific policies on reducing transport emissions:

I think a big issue in transport specifically is that there is a limitation of the data that we have available, it is very difficult to extrapolate what a specific policy would [achieve]...because we just lack statistics, some things we just can't count at the moment. (R9)

This is applicable both to modeling emission pathways, as well as the accuracy of forecasts, given that the effect of different policy measures is unclear. R5 explained that the lack of accuracy in making forecasts is a further barrier to policy development:

Forecasts...are more informed guesses than anything else, so if we have the target to reduce $\mathrm{CO}_{2}$ emissions by 2050 and this goal was set in 2011 in the Transport White Paper, it's difficult to see how these targets can be met accurately. So maybe a lack of forecasting accuracy is also an obstacle. (R5)

It was suggested that additional resource within the DGs was needed to overcome this barrier:

A simple step would be to have someone whose job was to be modelling all the different steps we're taking and working out whether we're on track or not for the $60 \%$ reduction target. It's three years now since we published the White Paper, we should have analysis of the contribution that's going to come from behaviour change, from efficiency improvements, from technology improvements, from infrastructure, we should have a clear modelling like they do for all the other industrial sectors of how we're going to deliver. (R12)

However it seems that rather than dedicating resource to modelling whether transport is on track to meet is reduction commitments, there is instead reliance within the DGs on a pervasive assumption that decarbonization obligations will be met through technological innovation.

\section{Overreliance on technology}

With regard to the policy strategies implemented to achieve emission cuts, policy officers suggested that these largely rely on technology change, even though it remains unclear whether this is a strategy that can contribute to significant emission reductions in the longerterm future. As one respondent suggested, 'I think you're very dependent on the market and entrepreneurs to really come up with new business models.' (R9)

One policy officer explained a tendency within the DGs to over-rely on 'silver bullet' technological innovations to mitigate transport's emissions so that reduction objectives and timelines would be met. But this was tempered by pointing out that most of the 'hyped' technologies are unrealistic and that the DGs themselves lack staff with the technical expertise to gauge the feasibility of the technologies:

...there's a very strong tendency to want to jump to silver bullet solutions. ...And I think part of the problem is there aren't enough people who have enough sort of technical background to know that these solutions aren't that wonderful. ...And so I 
think there are some very unrealistic ideas that tend to get support. And so you see this a lot in terms of enthusiasm for alternative energies and so on, where you have these hype cycles and waves of enthusiasm...Back around about 2000 there was this period of massive enthusiasm for hydrogen, and everybody was saying there would be a million hydrogen fuel cell cars on the road by 2010 and we haven't seen any of them. And then five years later it was biofuels that were flavour of the month... of course that's all got very discredited. (R11)

A considerable part of the EU's decarbonization strategy consequently depends on new technologies that do not as yet exist. Yet within this overreliance on technology, there seems to be a privileging of the need for technical expertise among policy offers, potentially at the expense of other forms of expertise that could help balance the reliance on technology with other socio-structural mechanisms.

\section{Discussion}

Interviews show that policy officers have diverging ideas of the level of decarbonization that needs to be achieved in the transport sector and over which timelines; whose responsibility policy development and implementation are; and through which concrete measures cuts in emissions can be achieved. This is also reflected in the assumption of differing viewpoints regarding legislative answerability, as individual policy officers feel responsible for progress on climate change mitigation, while others consider climate policy to be outside their work obligations. Expectations regarding the suitability of current and planned legislation to achieve transport decarbonization goals are consequently mixed, including perspectives of disinterest, optimism and deep concern. Interviews reveal that central barriers to progress on transport mitigation policies are partially internal, i.e. a result of poor intra- and inter-DG communication processes and a lack of agreement on common goals. This includes the measurability of progress towards emission reduction goals as a result of specific policies, and is reflected in calls for leadership on climate change mitigation. The lack of coordination revealed by the findings, both within and across DGs, supports previous studies recognizing that the internal coordination structures of the European Commission are crucial to understanding policy development. Christiansen's (1997: 78) observation still rings true today: when 'DGs have to co-operate on a matter of Union policy', inter-departmental conflict over sectoral interests typically leads to 'loggerheads'. While complex governance processes will always fall in the responsibilities of various administrative units, Hartlapp et al. (2014: 244) observe that the Commission's "internal coordination rules are difficult to circumvent today" and that the rules "still provide caveats or anchor points that may be used strategically". This was evidenced by DG MOVE's favoring of economic goals over GHG cuts, with the latter strategically seen as the responsibility of CLIMA. The results add complexity to governance models as for instance presented by Marsden and Rye (2010), as they indicate that even though official goals may exist, differing understandings of their implications and diverging priorities constitute barriers to progress within the internal workings or 'black box' of climate governance.

In comparison to these internal issues, 'external barriers' include opposition from member states, the favoring of economic goals over cuts in GHG emissions, pressure from industry and lobby groups, the preferential treatment of aviation and automobility over more sustainable transport modes, long periods of time needed for policy implementation, the lack of policy targeting monitoring, and an overreliance on technologies to contribute to emission reductions. As outlined by various policy officers, progress on climate policy may be slowed down by member states and in particular transport ministers. Marsden and Rye (2010) show 
that the opposite is also possible, as more ambitious UK climate policy initiatives requiring EU action have not been taken up - this, however, appears to have been an exception to the general rule of transport policy-making. In some cases, climate policies may also have been blocked by heads of state, as in the case of $\mathrm{CO}_{2}$ emission standards for cars, a policy initiative that was opposed by the German chancellor (BBC 2013). Interrelationships between different policy levels are thus complicated, because policies at supranational and national levels have to be integrated, and because policy officers at EU level as well as transport ministers at national levels can delay policy development or refuse policy implementation. This is a barrier involving national interests, and hence difficult to overcome; yet, this is an insight providing an explanation for the observed implantation gap (Banister and Hickman 2013).

Policy officers have suggested that economic goals dominate decision-making in the EU, supporting Nykvist and Whitmarsh's (2008: 1378) suggestion that 'sustainability is still not a dominant concern in European policy-making', with the '”jobs and growth" agenda' given priority over environmental concerns. Yet, there is ample evidence that decisions are based on non-comprehensive economic assessments. For example, policy officers have outlined that the environmental costs of transport are not internalized. This view is shared by economists, with for example Stiglitz (2006) considering the failure to charge for GHG emissions a subsidy to aviation, while economic assessments of the benefits of aviation regularly fail to report on the scale of subsidies provided to the sector (Gössling et al. 2016). With regard to automobility, detailed studies indicate that the cost of automobility to society is significant, and not covered by taxes (Gössling and Choi 2015). Overall, there is evidence of a wide range of energy subsidies with environmentally negative outcomes (van Beers and van den Bergh 2001; OECD 2003). This would indicate that economic assessments of transport benefits are incomplete, raising questions regarding the favoring of economic goals over cuts in GHG.

The influence of lobby groups on public policies in transport has been recognized for a long time, with for instance representatives of the road lobby 'active in trying to "sell" specific policy options', which further their interests (Marsden \& Stead 2011). Norton (2008) describes how US car lobby groups had to co-operate in order to annex public space that, up to the 1920s, largely belonged to pedestrians, cyclists, horse-drawn carriages, and public transport. In the period 1927-1955, tram systems were bought by front companies of the automotive industry in at least 45 US cities, with the sole purpose to remove these to create space for cars (Urry 2013). Likewise, aviation is a system kept alive and developed by public subsidies (Doganis 2006; Partnership of for Open and Fair Skies 2015). ICAO's non-action on emission growth is now widely accepted (Lindenthal 2014). Marsden and Rye (2010: 677) conclude that "the influence of powerful lobby groups on a consensus-led political process appears capable of slowing progress", an insight confirmed by several policy officers. Klüver's (2013: 81) case study of interest group influence on the European policy proposal for the reduction of $\mathrm{CO}_{2}$ emissions from cars showed how interest group influence during the policy formulation stage was pivotal to the Commission's final policy proposal: successful lobbying by the German Automotive Manufacturers' Association (VDA) was shown to have shifted the Commission from the pro- to the anti-environmental end of the policy scale and "thus towards the traditional automobile industry".

The present research furthermore adds the insight that a share of senior policy officers are recruited from industry, supporting Kassim et al.'s (2013) observation that EU officials are not necessarily 'career bureaucrats', but are instead often recruited from other professional backgrounds. A less-discussed implication of this is that it may introduce a personal bias towards favouring industry interests. It is known, on the national policy level, that politicians are not necessarily independent. As an example, a former German transport minister is a 
current member of the board of various lobby organisations and the president of the VDA (vda 2015). It is also known that heads of state have blocked EU-wide emissions standards policy (BBC 2013), while it was later revealed that these had received party funding by the car industry (Handelsblatt 2013).

Policy officers have highlighted that auto- and aeromobility remain insufficiently addressed in climate policy and that these may also be treated preferentially in comparison to more sustainable transport modes, echoing academic assessments (e.g. Banister and Hickman 2013). While this may be partially related to the belief that aviation and automobility are economically too important for Europe, it was also suggested that climate policy for these sectors may face barriers rooted in personal interests: as one policy officer outlines, policymakers' own lifestyles may be deeply entangled in the system of aeromobility. The existence of incomplete economic assessments, the influence of lobbying, and personal benefits related to aeromobility may consequently constitute other factors explaining the implementation gap; though it may also be argued that any policy officer highlighting these issues will be at risk of interfering with transport taboos (Gössling \& Cohen 2014), effectively jeopardizing one's position and standing within the DGs.

As some policy officers suggested, policy development at supranational level has considerable potential for opposition, refusal and delays, as EU member states may choose not to implement EU policy. In their discussion of decarbonization in the transport sector, van Lier and Macharis (2015: 133) concluded that "[c]ooperation across different levels of governance (global, EU, member state and regional/local levels) for sharing best practices and ensuring coordinated and effective approaches remains a crucial challenge in order to develop coherent policy measures in transport to reduce GHG emissions". The authors note how policy harmonization at the global level can slow down the regulatory process in the EU. In the case of aviation, ICAO has failed to present any significant climate policy for 18 years, forcing the EU to enact its own policy, i.e. the integration of aviation in its ETS (Lindenthal 2014; Scott et al. 2012). In the case of automobility, introduction of fuel taxes is, in the view of policy officers, progressing slowly or blocked completely: in this case, EU policies are delayed by member states, raising the question whether the politics of the principle of subsidiarity in the EU need to be reconsidered in the context of climate change.

Without modeling and monitoring, it is difficult to assess GHG emission trends and the success of mitigation strategies. Policy officers are concerned that forecasting tools are insufficiently used, and that there is a general lack of data. Yet, it would seem relevant to assess the specific outcomes of different policy initiatives, also with a view to identify the most (cost) efficient measures to reduce emissions. A considerable share of emissions related to bunker fuel use remains currently unaccounted for. This situation is a barrier to inter- and intra-DG agreement on emission trends in relation to goals, and the need for additional measures. Notably, the failure to integrate modeling efforts, including economic elements, may also explain the paradoxical situation that the EU has decided to commit to the most moderate emission reductions in the immediate future, i.e. when they involve low costs, and to achieve considerably steeper emission reductions in the medium- and long-term future, when each additional ton of $\mathrm{CO}_{2}$ reduction is projected to become significantly more expensive (IPCC 2014).

The notion that technological innovation will be insufficient to achieve required emission reductions is not new. The OECD (1991) suggested 25 years ago that taxes would be needed to achieve emission reductions, while subsidies and 'price support measures' would also have to be addressed. In 1999, the organization noted in the context of its sustainable transport 
modeling efforts that "the EST [Environmentally Sustainable Transport] criteria will likely not be met by technology alone. Indeed, contrary to much of current transport and environment policy, the results ... suggest that attainment ... will require at least as much focus on changing transport-related behavior as on improving vehicles, fuels, and infrastructure" (OECD 1999: 14). Notably, with regard to the latter, reducing the size and power of vehicles has been considered a key technological requirement to reduce energy use. As purchases of large cars continue to grow (Statista 2015), behavioral change may at least partially explain emission growth. Furthermore, as highlighted by policy officers, anticipated technical breakthroughs - the hydrogen car, the electric car, the car running on biofuels have not materialized. This sentiment is supported by Bakker (2010), who shows that hydrogen car hypes have been inflated by the car industry, while in aviation, media discourses of technological innovation have influenced public opinion over decades (Peeters et al. 2015). In the context of this situation, OECD has thus maintained for two and a half decades that carbon pricing and the reduction of fossil-fuel subsidies are key policies to achieve emission reductions (e.g. OECD 1991, 1999, 2005, 2008, 2015).

Overall, the findings provide new insight into policy development at EU level. They confirm the existence of an implementation gap with regard to far-reaching transport policies, adding to the more general understanding of agenda setting, policy formulation, decision-making and internal coordination (Hartlapp et al. 2014, Howlett et al. 2009) that has been discussed in earlier studies of EU transport policy (e.g. Klüver 2013; Lier and Macharis 2015). Importantly, findings suggest that path dependency as a phenomenon is not purely institutional, rather it is a phenomenon emerging from complex interrelationships between both institutional (structural) and individual (agency-based) factors: actions taken by policy officers are restricted by the rules, provisions, and workings of the EU policy system and its (in)efficiency and (in)flexibility in admitting change; and they are guided by policy officers' personalities and (perceived or real) external pressures influencing personal viewpoints. In combination, these constitute very significant barriers to the implementation of 'serious' climate policy.

These insights have considerable importance for the assessment of climate transport policy in the EU, and specifically the work of the European Environment Agency's annual Transport and Environment Reporting Mechanism (EEA 2015b), with the EEA (2015a,b) already having expressed critical views on the efficiency of these policies to achieve desired emission reductions. Furthermore, findings indicate that political scientists, transport geographers and others need to conceptualise and conduct research into path dependency at the EU level with a view to understanding the structural and individual barriers that prevent progress on climate policy within the EU.

\section{Conclusions}

This paper has had a starting point in Banister and Hickman's (2013) 'implementation gap', i.e. the observation that scientific insights are not translated into transport policies far reaching enough to achieve climate mitigation objectives (see also Anable et al. 2012; Banister 2008, 2011; Chapman 2007; Marsden and Rye 2010). As scientific findings may be considered input for the design of transport systems and policies to implement such systems a form of output, the internal workings of the European Union policy making process have been evaluated on the conceptual basis of a 'black box', within which scientific insight becomes a form of (insufficient) policy. To understand processes within the black box, the perspective of the policy officers themselves was investigated. Findings shed new light on the 'implementation gap', suggesting that there exist a number of vital reasons why significant 
climate policy for the transport sector is not being effectively developed at the EU supranational level and implemented in member states. The concluding key insights that have been uncovered by this study can be summarized as:

- Even though official goals exist, there is a lack of agreement between policy officers on the level of decarbonization that needs to be achieved in the transport sector, over the timelines for implementation, and who is responsible for the corresponding policy development.

- Some policy officers believe that economic goals are favored by DG MOVE over cuts in GHGs for the transport sector.

- A share of senior policy officers within the European Commission are recruited from industry, which facilitates higher pressure from the transport industry on public policy development.

- Policy officers' own lifestyles may be entangled in the system of aeromobility, giving them a personal interest in continued existence of contemporary transport system structures.

- There are insufficient forecasting tools, and a general lack of data, which make it difficult to assess transport GHG emission trends and the success of mitigation strategies. This is a barrier to inter- and intra-DG agreement on the need for additional policy measures.

- The assumption that technological innovation will largely solve the transport emissions problem is embedded in policy-maker perspectives, despite anticipated technical breakthroughs not materializing.

- Stronger leadership on climate mitigation for the transport sector is needed within and between DGs at the highest levels.

Interviews with policy officers, though not representative, have consequently led to the identification of a range of internal and external barriers to the formulation of climate change policies. Failure to overcome these barriers will confirm 'path dependency' and social lock-in in the transport sector, whereby alternative futures become impossible (Hall 2013; Imran and Pearce 2015; Schwanen et al. 2011). As Creutzig et al. (2015: 912) warn, there is little "appetite among policy-makers for seriously discussing thorny transport issues...unless this changes swiftly, transport may remain a roadblock to the world's efforts to mitigate climate change."

This research has furthermore contributed at a theoretical level on the nature of path dependency in EU policy for the transport sector, with potential relevance for other sectors. Path dependency has been shown in this study to be more than institutional: it emerges from complex interrelationships between both structural and agency-based factors. An implication of this is that those who seek to conduct research into path dependency in EU policy will need to conceptualise it relationally, as both institutional and individual. This is a significant insight for researchers who wish to better understand policy-making dynamics at the EU level.

Overall, this calls for considerably more significant policies for the transport sector, and a discussion of the EU's subsidiarity principle in the face of a growing gap between emission trends and policy targets. Future research should further investigate the internal workings of transport policy-making in the EU, based on wider interviewing strategies, and more systematic sampling approaches, while also focusing on the structural mechanisms and individual actors blocking or preventing decarbonization initiatives. 


\section{References}

Airbus (2015). Global Market Forecast 2015-2034. Available at: http://www.airbus.com/company/market/forecast/ Accessed 1 October 2015.

Anable, J., Brand, C., Tran, M. and Eyre, N. (2012). Modeling transport energy demand: a socio-technical approach. Energy Policy 41, 125-138.

Bakker, S. (2010). The car industry and the blow-out of the hydrogen hype. Energy Policy, 38(11), 6540-6544.

Banister, D. and Hickman, R. (2013), Transport futures: Thinking the unthinkable. Transport Policy 29: 283-293.

Banister, D., (2008). The sustainable mobility paradigm. Transport Policy 15 (1), $73-80$.

Banister, D., (2011). Cities, mobility and climate change. Journal of Transport Geography 19 (6), 1538-1546.

Banister, D., Stead, D., Steen, P., Åkerman, J., Dreborg, K., Nijkamp, P. and SchleicherTappeser, R. (2000). European transport policy and sustainable mobility. London: Routledge.

Barr, S., Shaw, G., Coles, T., and Prillwitz, J. (2010). "A holiday is a holiday": Practicing sustainability, home and away. Journal of Transport Geography, 18(3), 474-481.

Bart, I. L. (2010). Urban sprawl and climate change: A statistical exploration of cause and effect, with policy options for the EU. Land Use Policy, 27(2), 283-292.

BBC (2013). Germany delays EU limit on CO2 emissions from cars. Available at: http://www.bbc.co.uk/news/world-europe-24532284. Accessed 14 November 2015.

Boeing (2015). Current Market Outlook 2015-2034. Available at: http://www.boeing.com/resources/boeingdotcom/commercial/about-ourmarket/assets/downloads/Boeing_Current_Market_Outlook_2015.pdf. Accessed 10 August 2016.

Bows, A., \& Anderson, K. L. (2007). Policy clash: Can projected aviation growth be reconciled with the UK Government's 60\% carbon-reduction target?. Transport Policy, 14(2), 103-110.

Chapman, L. (2007). Transport and climate change: a review. Journal of Transport Geography, 15(5), 354-367.

Chèze, B., Chevallier, J., \& Gastineau, P. (2013). Will technological progress be sufficient to stabilize CO 2 emissions from air transport in the mid-term? Transportation Research Part D: Transport and Environment, 18, 91-96.

Christiansen, T. (1997). Tensions of European governance: Politicized bureaucracy and multiple accountability in the European Commisson. Journal of European Public Policy, 4(1), 73-90.

Creutzig, F., Jochem, P., Edelenbosch, O.Y., Mattauch, L., van Vuuren, D.P., McCollum, D. and Minx, J. (2015). Transport: A road block to climate change mitigation? Science, 350(6263), 911-912.

Decrop, A. (2004). Trustworthiness in qualitative tourism research. Qualitative research in tourism: Ontologies, epistemologies and methodologies, 156-169.

Doganis, R. (2006). The Airline Business. 2nd edition. London: Routledge. 
Dupont, C. And Oberthür, S. (2015). Decarbonization in the European Union: Internal Policies and External Strategies. Basingstoke: Palgrave Macmillan.

EC (2011) COMMISSION STAFF WORKING DOCUMENT. Accompanying the White paper. Roadmap to a Single European Transport Area - Towards a competitive and resource efficient transport system, COM (2011) 144 final, Brussels, European Commission.

EC (European Commission) (2015a). http://ec.europa.eu/transport/factsfundings/statistics/doc/2015/pocketbook2015.pdf Accessed 28 May 2016.

EC (European Commission) (2015b). 2030 Energy Strategy. Available at:

http://ec.europa.eu/energy/en/topics/energy-strategy/2030-energy-strategy Accessed 13

November 2015.

EC (European Commission) (2015c). About us. Available at: http://ec.europa.eu/clima/aboutus/mission/index_en.htm Accessed 25 November 2015.

EC (European Commission (2015d). About us. Available at:

http://ec.europa.eu/dgs/environment/index_en.htm Accessed 25 November 2015.

EEA (European Environment Agency) (2015a). Trends and projections in Europe 2015 Tracking progress towards Europe's climate and energy targets. Available at: http://www.eea.europa.eu/publications/trends-and-projections-in-europe-2015 Accessed 2 November 2015.

EEA (European Environment Agency) (2015b). Evaluating 15 years of transport and environmental policy integration. EEA Report No 7/2015. Available at: http://www.eea.europa.eu/publications/term-report-2015 Accessed 28 May 2016.

Gössling, S. and Choi, A. (2015). Transport transitions in Copenhagen: Comparing the cost of cars and bicycles. Ecological Economics, http://dx.doi.org/10.1016/j.ecolecon.2015.03.006.

Gössling, S. and Cohen, S. (2014). Why sustainable transport policies will fail: European Union climate policy in the light of transport taboos. Journal of Transport Geography, 39:197-207.

Gössling, S., Fichert, F., Forsyth, P. and Niemeier, H.-M. (2016). Subsidies in Aviation, submitted.

Hall, C.M. (2013). Tourism and Social Marketing, London: Routledge.

Handelsblatt (2013). "BMW hat Merkel im Sack". Available at:

http://www.handelsblatt.com/politik/deutschland/riesen-spende-an-die-cdu-bmw-hat-merkelim-sack/8934938.html Accessed 25 November 2015.

Hartlapp, M., Metz, J. and Rauh, C. (2014). Which Policy for Europe? Power and Conflict inside the European Commission. Oxford: Oxford University Press.

Higham, J.E.S., Cohen, S.A., and Cavaliere, C.T. (2014). Climate change, discretionary air travel and the 'flyers' dilemma'. Journal of Travel Research, 53(4): 462-475.

Howlett, M., Ramesh, M. and Perl, A. (2009). Studying Public Policy: Policy Cycles \& Policy Subsystems, Oxford: Oxford University Press.

IATA (International Air Transport Association) (2011). Vision 2050. Available at: http://www.iata.org/pressroom/facts_figures/Documents/vision-2050.pdf Accessed 28 May 2016.

IEA (International Energy Agency) (2015). World Energy Outlook. Available at: http://www.worldenergyoutlook.org/resources/energysubsidies/fossilfuelsubsidydatabase/ Accessed 12 November 2015. 
IMF (International Monetary Fund) (2015). How large are global energy subsidies? Available at: https://www.imf.org/external/pubs/ft/wp/2015/wp15105.pdf Accessed 12 November 2015.

Imran, M., and Pearce, J. (2015). Discursive Barriers to Sustainable Transport in New Zealand Cities. Urban Policy and Research, (ahead-of-print), 1-24.

IPCC (Intergovernmental Panel on Climate Change) (2014). Climate Change 2014:

Mitigation of Climate Change. Contribution of Working Group III to the Fifth Assessment Report of the Intergovernmental Panel on Climate Change [Edenhofer, O., R. Pichs-Madruga, Y. Sokona, E. Farahani, S. Kadner, K. Seyboth, A. Adler, I. Baum, S. Brunner, P. Eickemeier, B. Kriemann, J. Savolainen, S. Schlömer, C. von Stechow, T. Zwickel and J.C. Minx (eds.)]. Cambridge University Press, Cambridge, United Kingdom and New York, NY, USA.

Kassim, H., Peterson, J., Bauer, M.W., Connolly, S., Dehousse, R., Hooghe, L. \& Thompson, A. (2013). The European Commission of the Twenty-First Century. Oxford University Press: Oxford.

Klüver, H. (2013). Lobbying in the European Union: Interest Groups, Lobbying Coalitions and Policy Change. Oxford: Oxford University Press.

Kohler-Koch, B. and Eising, R. (Eds) (1999). The transformation of governance in the European Union. London: Routledge.

Kousoulidou, M., \& Lonza, L. (2016). Biofuels in aviation: Fuel demand and CO 2 emissions evolution in Europe toward 2030. Transportation Research Part D: Transport and Environment, 46, 166-181.

Lincoln, Y.S., and Guba, E.G. (1985). Naturalistic Inquiry. Newbury Park, CA: Sage.

Lindenthal, A. (2014). Aviation and climate protection: EU leadership within the International Civil Aviation Organization. Environmental Politics, 23(6), 1064-1081.

Lynn Jr, L. E., Heinrich, C. J., and Hill, C. J. (2001). Improving governance: A new logic for empirical research. Georgetown University Press.

Marsden, G., and Rye, T. (2010). The governance of transport and climate change. Journal of Transport Geography, 18(6), 669-678.

Marsden, G., and Stead, D. (2011). Policy transfer and learning in the field of transport: A review of concepts and evidence. Transport Policy, 18, 492-500.

McKercher, B., Prideaux, B., Cheung, C., and Law, R. (2010). Achieving voluntary reductions in the carbon footprint of tourism and climate change. Journal of Sustainable Tourism, 18(3), 297- 317.

Michaelowa, A. (1998). Impact of interest groups on EU climate policy. European Environment, 8(5), 152-160.

Miles, M. B., and Huberman, A. M. (1994). Qualitative data analysis: An expanded sourcebook. Sage.

Norton, P. D. (2008). Fighting traffic: the dawn of the motor age in the American city. MIT Press.

Nykvist, B. and Whitmarsh, L. (2008). A multi-level analysis of sustainable mobility transitions: Niche development in the UK and Sweden. Technological Forecasting \& Social Change, 75, 1373-1387.

O’Reilly, K. (2005). Ethnographic Methods. London: Routledge. 
OECD (2003). Environmentally Harmful Subsidies: Policy Issues and Challenges. OECD, Paris.

OECD (Organisation for Economic Co-operation and Development) (1991). Energy Prices, Taxes and Carbon Dioxide Emissions. OECD Economic Studies 17, Autumn 1991. Paris: OECD.

OECD (Organisation for Economic Co-operation and Development) (1999). Project on Environmentally Sustainable Transport (EST). Report NV/EPOC/PPC/T(99)3/FINAL/REV1. OECD: Paris.

OECD (Organisation for Economic Co-operation and Development) (2005). Environmentally Harmful Subsidies. Challenges for Reform. Paris: OECD.

OECD (Organisation for Economic Co-operation and Development) (2008). The Economics of Climate Change Mitigation. Policies and Options for the Future. Paris: OECD.

OECD (Organisation for Economic Co-operation and Development) (2015). OECD Companion to the Inventory of Support Measures for Fossil Fuels 2015. Available at: http://www.keepeek.com/Digital-Asset-Management/oecd/energy/oecd-companion-to-theinventory-of-support-measures-for-fossil-fuels-2015_9789264239616-en\#page1 Accessed 12 November 2015.

Partnership for Open \& Fair Skies (2015). Massive Subsidies are distorting the internationall aviation market. Available at: http://www.openandfairskies.com/wpcontent/themes/custom/media/White.Paper.pdf Accessed 1 October 2015.

Patton, M.Q. (2002). Qualitative Research and Evaluation Methods. Thousand Oaks, CA: Sage.

Peeters, P., Higham, J., Kutzner, D., Cohen, S. and Gössling, S. (2015). Are technology myths stalling aviation climate policy? Transportation Research Part D, submitted.

Richardson, J., \& Mazey, S. (Eds) (2015). European Union: power and policy-making. London: Routledge.

Schwanen, T., Banister, D., and Anable, J. (2011). Scientific research about climate change mitigation in transport: a critical review. Transportation Research Part A, 45: 993-1006.

Scott, D, Gössling, S., and Hall, C.M. (2012). Tourism and climate change: Impacts, adaptation and mitigation. London: Routledge.

Statista (2015). Anzahl der produzierten SUVs in Europa in den Jahren 2013 bis 2018 [Number of SUVs produced in Europe between 2013-2018]. Available at: http://de.statista.com/statistik/daten/studie/432619/umfrage/suv-produktion-in-europa/ Accessed 18 November 2015.

Stiglitz, J.E. (2006). A new agenda for global warming, Economists' Voice, July 2006.

Suykens, J. A., \& Vandewalle, J. P. (Eds) (2012). Nonlinear Modeling: advanced black-box techniques. Berlin: Springer Science \& Business Media.

UBA (Umweltbundesamt) (2015). Treibhausgas-Emissionen [Greenhouse gas emissions]. Available at: https://www.umweltbundesamt.de/themen/klima-energie/treibhausgasemissionen. Accessed 13 November 2015

Urry, J. (2013). Societies beyond oil: Oil dregs and social futures. London, Zed Books. van Beers, C and van den Bergh, J. (2001). Perseverance of perverse subsidies and their impact on trade and environment. Ecological Economics 36: 475-486. 
van Lier, T. and Macharis, C. (2015). Transport: Addicted to Oil. In C. Dupont \& S. Oberthür (Eds.) Decarbonization in the European Union: Internal Policies and External Strategies, pp. 115-136, Basingstoke: Palgrave Macmillan.

vda (Verband der Deutschen Automobilindustrie) [German Association of the Automotive Industry] (2015). Available at: www.vda.de 14 November 2015. 